\title{
¿EXISTE LA PROPIEDAD SOCIAL?
}

1

Desde hace algún tiempo, el lenguaje jurídico y el lenguaje político peruanos se han enriquecido con un nuevo término: la "propiedad social". Sin embargo, no hay consenso sobre lo que significa esta expresión y tanto los juristas como los políticos pretenden examinar la naturaleza de esta nueva institución. En consecuencia, parece oportuno apersonarse en el debate y tomar parte en el juego de definir la propiedad social. Para ello, la perspectiva de este artículo será fundamentalmente juridica. Sin embargo, mis propias convicciones sobre 10 que es el Derecho me llevan a evitar una separación demasiado cuidadosa entre Derecho y Política; o, cuando menos, me obligan a explicitar las condiciones en que se produce tal separación y a analizar las relaciones que surgen entre estas perspectivas, después de que han sido previamente aisladas ... por razones también de política.

En términos generales, aparentemente todo el mundo acepta que se está hablando de una forma de "propiedad", es decir, de un derecho real. Las diferencias de opiniones estriban en que algunos sostienen que se trata de una nueva institución -la propiedad de la sociedad- que no es asimilable a ninguno de los tipos anteriores. En cambio, quienes no pueden liberarse de las categorías conceptuales impuestas por la tradición, tienden a negar la especificidad de la propiedad social para clasificarla como: (a) propiedad del grupo de trabajadores de la empresa; (b) propiedad del Sector de Empresas de Propiedad Social; o (c) propiedad estatal.

La expresión "propiedad social" ha sido utilizada en el Perú por un Anteproyecto de Ley (setiembre 1973) que en su artículo $3^{\circ}$ define a esta forma de propiedad por el hecho de que "corresponde al conjunto de trabajadores que laboran en las Empresas de Propiedad Social, sin que a ninguno de ellos le correspondan derechos de propiedad individual" y por el hecho de que "al generar nuevas unidades económicas de la misma naturaleza, beneficia a la Sociedad". Esta definición es, a todas luces, pobre y, como veremos después, inexacta. En la Introducción del mismo Anteproyecto de Ley se precisa que no se trata de una forma especial de propiedad privada, de un grupo de trabajadores por más numeroso que sea; ni tampoco es una forma especial de propiedad estatal. Más bien, se afirma, la propiedad corresponde a la sociedad como un todo y los trabajadores se limitan a usarla. En consecuencia, mientras que el articulado del anteproyecto se inclina por la tesis de la propiedad del Sector - al menos en su aspecto declarativo - la Introducción que presenta dicho articulado opta por la tesis más novedosa de la propiedad de la sociedad.

Sin embargo, la expresión "propiedad social" no es indudablemente autóctona; ha sido utilizada en otros paises $y$, en particular, las democracias socialistas la han usado con sentidos diversos. En la U.R.S.S., propiedad social es fundamentalmente la propiedad estatal (1). Kolesov nos dice: "La diferencia radical de la propiedad socialista respecto de las normas precedentes de propiedad consiste en que es una propiedad social, colectiva" (2). Pero agrega: "La forma rectora de propiedad en la economía de los países

1. A pesar de que, cuando todos los bienes se encuentran bajo el control del Estado y no existe título oponible alguno, nos resulta difícil hablar de "propiedad". Si nadie más puede ser propietario, la propiedad estatal exclusiva se desvanece o se disuelve en categorías jurídicas diferentes.

2. KOLESOV, N.-"La propiedad social sobre los medios de producción en la U.R.S. S.”. Ediciones en Lenguas Extranjeras, Moscú, 1961, p. 63. 
de democracia popular la constituye la propiedad socialista del Estado" (3). "En la U.R.S.S. y las democracias populares, la propiedad del Estado no sólo constituye la forma dominante y rectora de la propiedad socialista, sino que también es la forma más desarrollada, la forma superior de la propiedad socialista. Es patrimonio de todo pueblo..." (4). Y aclara que no debe contraponerse propiedad social y propiedad estatal pues durante la dictadura del proletariado, en la que el aparato estatal debe sobrevivir, el Estado es el órgano que representa y organiza la sociedad (5). Más interesante para nuestra búsqueda de la naturaleza de la ipropiedad social es la experiencia yugoslava. En ella, la "propiedad social" adquiere una mayor especificidad: se organiza bajo los principios de la autogestión, lo que significa que los trabajadores de la empresa partcipan en el establecimiento de las relaciones de trabajo y en la gestión de la empresa, así como en el reparto de los beneficios (6). Se sostiene que la "propiedad social" no pertenece a ningún grupo ni al Estado sino que corresponde a la sociedad encarnada por los cuerpos representativos del pueblo trabajador (organismos politicos) y por los productores representados por sus organizaciones económicas autónomas (7). Sin embargo, una parte de los juristas yugoslavos consideran que aun asi se trata de propiedad del Estado; Rastovcan, por ejemplo, afirma que desde el punto de vista jurídico la sociedad no puede estar representada sino por el Estado, de manera que propiedad de la sociedad es propiedad del Estado (8). En cambio, otra parte de la doctrina yugoeslava, representada sobre todo por los juristas Finzgar y Kidric, creen que no carece de sentido hablar de propiedad de la sociedad (9).

En el otro extremo del espectro, las tendencias democristianas -que fueron las primeras que propug-

3. Ibid. p. 65 .

4. Ibid. p. 66 .

5. Ibid. p. 67 .

6. DJORDJEVICH, Jovan.-"Yugoeslavia, democracia socialista”. Fondo de Cultura Económica. México, 1961, p. 61 .

7. Ibid. p. 65 .

8. FERRETJANS, Jean-Pierre.-"Essai sur la notion de propriété sociale. De la propriété privée a la propriété collective: L'expérience yugoeslave de socialisation de l'agriculture". Libraire Générale de Droit et de Jurisprudence. Paris, 1963, pp. 203-205.

9. Ibid. pp. 208-212. naron en nuestro medio este tipo de organizaciones, bajo el nombre de "empresas comunitarias"- prefieren asignar la propiedad al grupo de trabajadores que labora en la empresa. Dentro de este orden de ideas, la empresa de propiedad social no diferiria de la empresa privada sino en el hecho de que se encuentra integrada exclusivamente por trabajadores. Sin embargo, una empresa de esta naturaleza es difícil de organizarse y es más difícil aún que conserve su carácter, si se quiere mantenerla como propiedad efectiva del grupo: o se otorga al trabajador una verdadera propiedad sobre su parte en la empresa y éste puede venderla a quien no es trabajador o transierirla mortis-causa, con lo que pronto la empresa cuenta nuevamente con trabajadores de un lado y dueños del capital del otro; o se niega al trabajador todo derecho de disposición sobre su cuota-parte y se condicionan los derechos de gestión y utilidades al tiempo que dura la prestación de servicios, con lo que la propiedad del trabajador se esfuma y nos encontramos en algunas de las otras posiciones antes reseñadas.

Mi tesis es que la empresa de propiedad social no es nueva forma de propiedad sino un nuevo tipo de persona jurídica. En consecuencia, las categorias de la propiedad no se aplican a las relaciones existentes entre los diversos elementos en torno a los cuales se estructura la empresa -trabajadores, Sector, Estado- sino únicamente a las relaciones entre la empresa como persona juridica y los bienes de su activo. Dentro de este orden de ideas, no tiene sentido preguntarse de quién es la Empresa de Propiedad Social y menos aún contestar que es del Estado, del Sector o de los trabajadores. En otras palabras, considero que la llamada "propiedad social" no es propiedad; y lo demostraré a continuación.

\section{II}

Ante todo, se hace necesario definir lo que entendemos por "propiedad". Solamente después de que nos encontremos de acuerdo sobre este parámetro, podremos juzgar la propiedad social en función de tal definición y saber si encuadra dentro de ella o no.

Sin embargo, la definición de la propiedad implica una distinción previa de carácter técnico que no se realiza habitualmente y cuya falta genera gran parte de la confusión que existe sobre esta materia. La 
propiedad puede ser entendida a dos niveles: en sentido sociológico y en sentido jurídico. $Y$ estos dos sentidos constituyen instrumentos conceptuales netamente diferenciados, que no puedn intercambiarse $y$ que arrojan consecuencias para el análisis marcadamente distintas.

En sentido sociológico, la propiedad es un hecho social configurado por la forma como un hombre o un grupo de hombres se apropia de ciertos bienes para los efectos de su utilización, sea como medios de producción, sea como artículos de consumo. Nos encontramos, pues, ante una situación fáctica y no ante una construcción jurídica. No importa la forma juridica empleada; de lo que se trata es de saber quiénes efectivamente controlan el bien. Poco Interesa si los "dueños" de los medios de producción se han organizado bajo la forma de una sociedad mercantil de responsabilidad limitada, bajo la forma de una sociedad anónima o si poseen el bien en condominio; lodo este revestimiento jurídico es considerado irrelevante y se tiende a develar las verdaderas unidades de poder encubierias por las formas jurídicas. Dentro de este orden de ideas, puede llegarse a la conclusión de que la sociedad anónima es una mera ficción y los "dueños" de los medios de producción son en realidad personas naturales que aportaron el capital y que pertenecen a una determinada clase "propietaria"; pero puede también concluirse en otros casos que "los dueños" (siempre en sentido sociológico) son quizá un grupo de altos ejecutivos que dominan lina masa de pequeños accionistas dispersos y poco informados. Por consiguiente, en sentido sociológico los "dueños" no son aquellas personas naturales o "morales" que tienen un derecho de propiedad (en sentido jurídico) sobre los bienes, sino aquellos que efectivamente detentan los bienes y los usan a su arbitrio.

Desde el punto de vista jurídico, la propiedad es una relación particular de derechos y obligaciones basada en la vinculación entre un "sujeto" de derecho y un objeto o bien. Para estos efectos, entendemos por "sujeto" un centro de imputación normativa, es decir, una unidad juridica (cuyo origen puede ser biológico, como en el caso de la persona natural, o técnico, en el caso de la persona "moral") que es capaz de ejercitar derechos y de asumir obligaciones. Entendemos por objeto, fundamentalmente una cosa corporal que puede ser mueble o inmueble. Planiol y Ripert señalan que no es adecuado hablar de "propiedad" del empleo o "propiedad" de la cátedra; en estos casos, se trata más bien del conjunto de garantias que la ley otorga al empleado o al profesor y no de un derecho de propiedad técnicamente hablando (10). Y Colin y Capitant afirman que la palabra "propiedad" sólo puede ser utilizada metafóricamente para hablar de propiedad del empleo, propiedad industrial, propiedad intelectual, etc., tratándose en estos casos de una extensión abusiva del término (11). De otro lado, la relación entre este sujeto $y$ este objeto no es simple en la propiedad; no consiste en un solo derecho sino en un conjunto de derechos y obligaciones que constituyen una "sltuación juridica".

Ahora bien, esta relación sujeto-objeto tiene caracteristicas particulares que son constitutivas de la esencia de la propiedad. En primer lugar, esta relación confiere siempre al titular del derecho las facultades de usar de la cosa, percibir sus frutos y disponer de ella, según la definición del Derecho romano ya hecha clásica: Jus utendi, jus fruendi et jus abutendi. De estas facultades, el jus abutendi o derecho de disposición es el más importante. Jorge Eugenio Castañeda nos dice que la nota esencial del dominio es la de conceder a su titular el derecho de disponer de una cosa; esto lo diferencia de los demás derechos reales. $Y$ agrega, siguiendo una extensa doctrina, que la propiedad es el más amplio poder de disposición que tenemos sobre un bien (12). Por eso, la jurisprudencia francesa ha considerado que, a pesar de todas las restricciones que pueda tener el derecho de propiedad en la época actual, no es posible establecer convencionalmente una inalienabili. dad absoluta y perpetua: la libre disposición de los bienes es un atributo esencial de la propiedad. Incluso, basta que la inalienabilidad haya sido pactada simplemente por mucho tiempo, para que la cláusula contractual que la establece se considere nula porque atenta contra el derecho de propiedad (13). Dentro de esa

10. PLANIOL, Marcel y RIPERT, Georges.--"Traité Pratique de Droit Civil Francais", III, No 215.

11. COLIN, A. y CAPITANT H.-"Cours Elémentaire de Droit Civil Français", 10a, ed., Paris, 1942, N" 883. 12. CASTAÑEDA, Jorge Eugenio.-"Instituciones de Derecho Civil. Los Derechos Reales", Lima, 1958, T.I. $\mathrm{N}^{\circ} 168$.

13. PLANIOL, M. y RIPERT, Georges--Op. cit., III, No 224. 
misma linea, el artículo 852 de nuestro Código Civll no permite que se establezcan prohibiciones de enajenar, salvo en los casos expresamente contemplados por la ley; y éstos últimos son indudablemente excepciones (comunidades de indígenas, fundaciones, hogar de familia) que, por el mismo hecho de la excepción, escapan en cierta forma a la noción del derecho de propiedad. Es interesante destacar cómo, dado que la noción de propiedad que he venido delineando ha sido creada y responde a las necesidades de una sociedad específica que se rige por los principios del mercado, las excepciones referidas se encuentran ubicadas en las áreas marginales de tal economía de mercado $y$ son en la práctica de escaso uso.

Otras características esenciales de la propiedad son las de ser un derecho absoluto, exclusivo y perpetuo. El calificativo de absoluto no se aplica obviamente a su uso, que actualmente se encuentra muy relativizado (el artículo 34 de la Constitución del Estado prescribe que la propiedad debe usarse en armonia con el interés social). Derecho absoluto significa aquí que es oponible a todo el mundo, en la medida cue cualquier otra persona tiene la obligación de respetarlo; se diferencia así de los derechos relativos que sólo generan obligación en determinadas personas, como el derecho del acreedor que tiene como contrapartida la obligación de un deudor específico. Derecho exclusivo significa que el titular y solamente el titular tiene derecho a ejercer los atributos de la propiedad: nadie que no sea el propietario -o quien tenga autorización de éste- puede disponer de la propiedad. Finalmente, derecho perpetuo quiere decir que la propiedad no se encuentra sometida a plazo. Evidentemente, la perpetuidad no implica que un solo propietario sea el titular del derecho sin que lo pueda transferir nunca; la perpetuidad no está referida a la persona del propietario sino al derecho mismo, al hecho que la posibilidad de que exista un derecho de propiedad sobre tal bien -cualquiera que sea la persona del propietario - no esté limitada por plazo alguno.

A estas características cabria agregar la independencia del derecho de propiedad respecto de todo otro derecho: su existencia misma no está subordinada o vinculada a nada, sino que existe autónomamente. La propiedad feudal —si cabe llamarla propiedad- está ligada a ciertos derechos politicos o a determinados status sociales que la condicionan o la limitan. Como una supervivencia de esa noción de propiedad, en el Perú han existido hasta mediados del siglo pasado los mayorazgos, las capellanías de familia y otras vinculaciones laicales que las ideas liberales fueron paulatinamente haciendo desaparecer. La propiedad moderna no admite esta existencia subordinada. Dentro de una sociedad de mercado, los bienes tienen fundamentalmente el carácter de mercancias: tienen que ser fácilmente intercambiables. Por esta razón, la propiedad pasa a ser un derecho de disposición puro, de manera que nada restrinja la circulación de los bienes económicos.

¿Qué se entiende por propiedad social? En un cierto sentido, toda propiedad es social. En primer lugar, porque la aparente relación sujeto-objeto esconde siempre una relación sujeto activo (titular)-sujetos pasivos (los demás integrantes de la sociedad), con referencia a un objeto determinado. En efecto, decir que una persona es propietaria de un objeto no es describir simplemente una relación entre esa persona y ese objeto; esencialmente, es indicar que existe una relación entre esa persona y las demás personas que están obligadas a rspetar esa propiedad. AI punto que no tendría sentido hablar de un "derecho de propiedad" si no existieran otras personas que podrian objetar tal apropiación y que sin embargo están obligadas a respetarla. Robinson Crusoe no puede decirse que tenía un "derecho" de propiedad sobre las tierras y demás bienes de su isla; se encontraba en una situación de facto que no requería reconocimiento social -es decir, garantía jurídica- en vista de que no existía sociedad. Por consiguiente, todo derecho es social, en la medida que la noción de Derecho supone el reconocimiento social de ciertas facultades. En segundo lugar, toda propiedad es social porque, como ya se ha dicho antes, su uso debe realizarse en armonia con el interés social. En la actualidad, ya no se concibe un uso indiscriminado y arbitrario de la propiedad que desconoce las exigencias de la sociedad y que pueda llegar hasta el abuso. Pero indudablemente no es este significado genérico del adjetivo "social" que quiere ser manifestado en la expresión "propiedad social". De lo que se trata no es de señalar que el derecho se realiza en el interior de una sociedad ni que el uso debe tener en cuenta a dicha sociedad; muy precisamente, lo que se pretende es encontrar un nuevo tipo de propiedad en la que el sujeto activo o titular del derecho es la sociedad entera. Examinaremos si esto se cumple en la Empresa de Propiedad Social. 
Preguntémonos, en primer lugar, cuáles son los bienes que pueden ser objeto de propiedad social. La respuesta es obvia: como en cualquier empresa, los bienes de su propiedad serán todos aquellos que conforman su activo, es decir, su local, sus maquinarias, su dinero, sus productos, etc. La Empresa de Propiedad Social dispone, entonces, de un activo constituído de acuerdo a los fines para los que ha sido organizada.

¿A quién pertenecen tales bienes? En otras palabras, ¿quién es el sujeto activo o titular del derecho sobre los bienes del activo? Desde el punto de vista jurídico, no cabe sino una respuesta: el titular o propietario es la empresa misma en tanto que persona juridica. Los bienes han sido adquiridos por la empresa y sólo ella puede aprovecharlos, usarlos y eventualmente enajenarlos. Los socios o integrantes de la empresa no tienen derecho alguno sobre el activo.

Ahora bien, hasta este punto, la Empresa de Propiedad Social no se diferencia de cualquier otro tipo de empresa y no encontramos todavia justificación para el adjetivo "social". En efecto, tomemos como ejemplo el caso de la sociedad anónima. Los bienes que utiliza para llevar a cabo sus actividades económicas no pertenecen a los socios sino a la sociedad anónima. Esta tiene personalidad jurídica, to que equivale a decir que es capaz de tomar decisiones propias y que éstas pueden incluso ser contrarias a la voluntad de los socios individualmente considerados; consecuentemente, la sociedad anónima es la titular del derecho de propiedad sobre su activo. Es así como la adquisición de tales bienes supone una transferencia de propiedad en su favor; y esta transferencia puede que sea realizada por uno de los socios mismos cuando, por medio de un contrato de compra-venta, de un aporte o de otra figura similar, enajena su propiedad en favor de la persona jurídica denominada sociedad anónima. De la misma manera, la sociedad puede enajenar sus bienes en favor de terceros o de sus propios socios - venta o reducción de capitalexistiendo también en estos casos una verdadera transferencia de dominio. Lo que demuestra que la sociedad anónima es quien ejerce efectivamente los derechos inherentes a la propiedad con relación a los bienes de su activo. En la Empresa de Propiedad Social la situación es la misma, aunque el control externo de los actos de esta persona juridica sea mayor que en el caso de la sociedad anónima. La Asamblea puede autorizar la venta de los activos fijos (art. 32, inc. c., del Anteproyecto). $Y$ el Comité Directivo puede vender los demás activos (art. 51, inc. a). Esto significa que la Empresa, a través de sus órganos competentes, ejerce los atributos de la propiedad y, en especial, el derecho de disposición.

Puede objetarse este planteamiento afirmando que la Empresa de Propiedad Social no es verdaderamente la propietaria de sus bienes por cuanto necesita una autorización de la Unidad Regional para perfeccionar la enajenación (art. 32, in fine). Además, el uso de tales bienes se encuentra seriamente limitado porque estas empresas está obligadas a integrarse en unidades superiores (art. 132) y a concertar y coordinar su acción (art. 133), de manera que su actividad -que implica el uso de sus bienes- se decide en conjunto y no por cada empresa separadamente. Eso significaría que tanto el derecho de disposición como el de administración se encuentra en el Sector; y el artículo 99 hace partícipe al Sector en las utilidades de la empresa, es decir, le asigna también un derecho a percibir los frutos. Esta interpretación que atribuye la propiedad al Sector se veria confirmada expresamente por el propio texto del Anteproyecto que en su artículo $3^{\circ}$, antes citado, señala que la propiedad corresponde al conjunto de trabajadores que laboran en todo el Sector; y que es precisamente este hecho el que le confiere su carácter social.

Sin embargo, las cosas no son lo que dicen sus etiquetas sino lo que su verdadera naturaleza establece; $y$, en el presente caso, cuando hablamos de naturaleza queremos referirnos a su naturaleza jurídica. Desde tal perspectiva, los artículos mencionados no son suficientes para atribuir la propiedad del activo de cada empresa al Sector; y la declaración del artículo $3^{\circ}$ implica un error de concepto. En efecto, nada de lo dicho hacer perder a la Empresa de Propiedad Social el jus utendi, el jus fruendi o el jus abutendi; $y$, a su vez, nada de lo dicho confiere estos derechos a las Unidades Regionales o a la Comisión Nacional de la Propiedad Social, que son los órganos de gobierno del Sector y a quienes correspondería su ejercicio si la propiedad fuera de todos los trabajadores que integran dicho Sector. Por consiguiente, de un lado, el derecho de propiedad de la empresa no se encuentra afectado y, de otro lado, 
no encontramos nada semejante al derecho de propiedad en poder del Sector.

En primer lugar, la necesidad de una autorización para la venta del activo implica una limitación al derecho de propiedad pero no atenta contra su existencia. Dentro del mundo actual, muchos bienes de particulares requieren que su venta sea autorizada por alguna dependencia del Estado; $y$, sin embargo, nadie duda que continúan siendo de propiedad privada. Es perfectamente conocido que las leyes sectoriales exigen que ciertos actos de las empresas que tienen repercusiones en la vida económica nacional sean previamente aprobados. Este es el caso, de los aportes -adquisición de propiedad-y de las reducciones de capital -enajenación de propiedad- en el Sector Industrias (arts. 169 y 212 del Reglamento del Decreto-Ley 18350). Y los ejemplos nacionales y extranjeros podrían multiplicarse. A pesar de ello, nadie ha sostenido que el establecimiento de tales requisitos legales ha significado una transferencia de los activos que eran propiedad de las empresas a la propiedad del Estado a partir de la dación de la Ley de Industrias. Y la razón para que no se haya formulado tan exótica interpretación estriba en que, tanto en esos casos como en la Empresa de Propiedad Social, el derecho de disposición continúa siendo exclusivo de la empresa. Es decir, solamente la empresa propietaria --sea una sociedad anónima - una Empresa de Propiedad Social- puede decidir la venta de los bienes de su activo; ella conserva la iniciativa y el Estado o la Unidad Regional se limitan a autorizar la decisión. Así el derecho de disponer de la propiedad -o capacidad de decidir la enajenación- sigue siendo exclusivo de la empresa propietaria. Por la misma razón, no puede decirse que el Estado o el Sector, según el caso, tengan derecho de disposición alguno pues de ninguna manera pueden decidir la enajenación del activo. Nada en el Anteproyecto de Ley confiere esta facultad a la Unidad Regional o a la Comisión Nacional; estas entidades sólo actúan como controladoras del ejercicio del derecho de propiedad de las empresas, pero no como sujetos del derecho de propiedad.

Más seria parece la objeción con relación al derecho de uso, inherente al derecho de propiedad. Es exacto que el Anteproyecto obliga a las empresas a agruparse en unidades mayores; respecto de este punto, no existe la libertad de asociación que constituye un correlato lógico de la propiedad privada indivi- dualista. Por otra parte, el Anteproyecto no ha precisado la naturaleza de la coordinación y concierto exig:dos en el interior de la unidad superior, ni tampoco la forma cómo se programará la producción a nivel regional o nacional (arts. 134 y 142). Incluso, el artículo 134, segundo párrafo, prescribe el intercambio de tecnologia entre las diferentes empresas, es decir, la circulación dentro del Sector de ciertos bienes que también constituyen parte del activo de la empresa; pero no se aclara si este intercambio se realizará mediante acuerdos mercantiles entre las empresas (lo que ratificaría el derecho de propiedad de cada empresa sobre la tecnología adquirida o generada por ella misma) o si se realizará obligatoriamente y libre de todo pago (lo que nos llevaría a pensar que, al menos respecto de la tecnología, nos encontramos ante una situación diferente a la del derecho de propiedad). Empero, a pesar de lo dicho, el Anteproyecto no parece suponer una planificación centralizada o la supresión de la economía de mercado ni siquiera en el interior del Sector de Propiedad Social. Por el contrario, las facultades que antes hemos mencionado con relación a la venta de su activo fijo y las facultades aún más amplias con relación a la venta de sus productos, permiten inferir que se conserva siempre la independencia de cada empresa; de manera que las vinculaciones entre ellas, - con las empresas privadas o estatales, tienen que realizarse generalmente mediante acuerdos libres. Por esta razón, el artículo 30 establece en su inciso (a) que compete a la Asamblea de cada empresa la aprobación de las políticas, planes y programas de su actividad; y el inciso (b) del mismo artículo asigna igualmente a la Asamblea la función de aprobar o desaprobar la gestión social. En su actividad cotidiana, la Empresa de Propiedad Social es administrada, como cualquier otra empresa, por sus órganos ejecutivos: el Comité Directivo y la Gerencia (arts. 42, 51, 53 y 55). De lo que se deduce que el uso de los bienes del activo está determinado por estos órganos de gobierno de la empresa. La coordinación y concierto no puede llegar al grado que anule esta capacidad de la empresa de administrar su propio patrimonio. En esta forma, el jus utendi existe siempre, aunque se encuentre sujeto también a limitaciones severas.

Finalmente, el jus fruendi no parece haber sido afectado. Cuando el artículo 4 9 declara que la acumulación social -que en el artículo $1^{\circ}$ se ha seña- 
lado como característica de esta nueva empresa- es el proceso mediante el cual se incorpora al patrimonio de la empresa o al del Sector el excedente resultante, no se está planteando a nivel jurídico ninguna forma revolucionaria ni nueva de percepción de los frutos. Explicaré este punto. Para los efectos de la tesis que estoy tratando de demostrar en el sentido que el activo de estas empresas pertenece a las personas jurídicas que las constituyen, es preciso verificar si los frutos -o utilidades o excedentes- de la propiedad del activo son apropiados por las propias empresas. Ahora bien, no cabe duda que la ley no priva a las empresas de los resultados de su actividad productiva, es decir, de sus productos; las Empresas de Propiedad Social hacen suyos los productos al igual que cualquier otra empresa. No se los entregan al Estado, ni al Sector; son los frutos de su propiedad y disponen de ellos en la forma más conveniente a sus intereses. La venta de estos frutos origina a su vez un excedente, luego de deducido el costo de producción; este excedente constituye, por así decirlo, el "fruto neto" que resulta de la utilización económica de la propiedad de su activo. Sin entrar en los tecnicismos de las diferentes clases de excedentes, lo importante es señalar que este excedente también es apropiado por la empresa que lo ha generado. Parte de dicho excedente contribuirá a formar capital y se incorporará al patrimonio de la empresa, como lo declara la primera frase del artículo 4 . Pero esto no cambia la situación ni convierte en social esta acumulación; por el contrario, también como en cualquier empresa, la persona jurídica que la encarna -en su calidad de titular del derecho de propiedad del activo $y$, consecuentemente, dueña de sus frutos- hace suyo dichos "frutos" y les da el uso que considera oportuno: los reinvierte o los reparte. De otro lado, la segunda frase del artículo 4 ? antes citado declara que la acumulación es social porque parte del excedente se incorpora en el patrimonio del Sector. Esta afirmación se refiere a lo dispuesto en el artículo 99, según el cual las Empresas de Propiedad Social deben transferir anualmente el $10 \%$ del excedente -calculado de manera que los aumentos salariales no puedan reducirlo - al Fondo Nacional de Propiedad Social. Sin embargo, esta obligación no altera el jus fruendi de la empresa: nadie discute el derecho de la empresa de hacer suyos los frutos; simplemente se le exige una contribución adicional para el Sector. Esta contribución tiene una natura- leza semejante a la del impuesto; y no es posible pensar que la aplicación de impuestos sobre la propiedad o sobre sus frutos constituye una supresión del derecho del propietario a la percepción de los mismos.

De toda la discusión que antecede se desprende que los bienes del activo de una Empresa de Propiedad Social pertenecen a esa empresa en tanto que persona jurídica. Por consiguiente, desde el punto de vista jurídico no hemos encontrado hasta aquí nada esencialmente diferente de la propiedad que ya conocíamos, nada que justifique jurídicamente el calificativo de "social". Esta justificación habría podido encontrarse, por ejemplo, en el hecho de que el activo no perteneciera a cada empresa sino al Sector o al Estado o a la comuna política u otra organización "social" similar; es decir, que los derechos de disposición, administración y goce hubieran sido conferidos a un sujeto "social". Esto no ha sucedido asi y no lo vemos posible dentro de los términos de una economía de mercado. Parece irrefutable que, en la medida que la sociedad se organice a través de unidades independientes y que éstas se relacionen entre sí de manera más o menos voluntaria, las instituciones juridicas de la propiedad privada y el contrato no pueden desaparecer ni serán alteradas en sus características esenciales. Indudablemente, su ejercicio estará sujeto a muy severas limitaciones, paralelas a las limitaciones a los principios del mercado que existan al nivel de la organización económica; pero en tanto subsista el mercado, subsistirán igualmente dichas instituciones. Distinto será el caso si la propiedad social se concibe dentro de una organización socioeconómica nacional que ha instaurado un régimen de planificación de la producción y en el que los productos se reparten por un procedimiento diferente al de la economia monetaria de mercado. En esta última hipótesis, difícilmente podría hablarse de propiedad cuando el sujeto o titular de la misma sería uno solo por definición -el Estado, la sociedad- y su título no sería oponible a nadie pues ninguna otra persona natural o jurídica podría pretender el mismo derecho; y cuando las facultades inherentes al derecho de propiedad se encuentran difuminadas por distintos organismos sociales.

Debe advertirse que el razonamiento que hemos seguido hasta ahora se basa en que las personas jurídicas sean consideradas sujetos de derecho al igual que las personas naturales. Por ese motivo, son sus- 
ceptibles de tener derechos de propiedad; y ei derecho de propiedad de una persona jurídica respecto de su activo es indiscutible y excluye todo derecho similar de los socios o de terceros sobre los mismos bienes. Sin embargo, si negamos esta premisa y sostenemos que solamente las personas naturales son auténticos sujetos de derecho, la conclusión de nuestro análisis puede ser sustancialmente diferente.

\section{IV}

Hemos afirmado que el titular del derecho de propiedad -el propietario- de los bienes del activo de una Empresa de Propiedad Social es la misma empresa como persona jurídica. Esta afirmación puede ser negada desde dos puntos de vista distintos: el jurídico y el sociológico. Los examinaremos separadamente.

Desde el punto de vista jurídico, la negación de la personalidad de los entes jurídicos conlleva negar también que sean estos entes los sujetos en quienes reside el derecho de propiedad; ésto nos obliga a buscar en las personas naturales que los integran al titular del derecho de propiedad. Si las personas jurídicas no existen como tales, los verdaderos propietarios de los bienes de su activo son sus socios; hará falta, entonces, deierminar los mecanismos juridicos en virtud de los cuales estos socios son propietarios de tales bienes. Dentro de este orden de ideas, creo que uno de los autores más agudos y consecuentes es Planiol, quien sostiene que no existen "personas" juridicas y que éstas no son sino propiedades colectivas que se esconden deirás de la ficción de la personalidad moral pero que subsisten hasta nuestros días como una forma encubierta de propiedad que es paralela a la propiedad individual (14). Sin embargo, en una obra posterior escrita conjuntamente con Georges Ripert, Planiol reconoce que esta teoría es muy discutida, sin dejar de manifestar su simpatía por ella (15).

En mi opinión, Planiol está profundamente equivocado en su apreciación. $Y$ esta equivocación obedece al hecho de haber confundido el plano jurídico

14. PLANIOL, Marcel.-"Traité Elementaire de Droit Civil”, I, Nos. 3016 y ss. y No 3046.

15. PLANIOL, Marcel y RIPERT, Georges.--"Traité Pratique de Droit Civil Français", I, No 68. con el plano sociológico. En primer lugar, creo que uno de los mayores sofismas que se encuentra muy en boga en la teoría jurídica contemporánea es el de sostener que todo bien sólo puede pertenecer a personas naturales y que toda persona jurídica debe a su vez resolverse en personas naturales, porque son éstas últimas las únicas que tienen existencia real. No cabe duda que, desde el punto de vista biológico, las personas naturales son las únicas que existen; pero la biología no es sino una perspectíva de la realidad. Paralelamente a ella, existen además realidades de otros órdenes, entre las que encontramos las realidades técnicas o jurídicas. La persona jurídica es una realidad, pero es una realidad técnica. Evidentemente que en última instancia, serán las personas naturales las beneficiarias de todo el aparato técnico, las que administrarán el patrimonio del ente técnico y las que constituyen dicho ente. Pero eso no contradice el hecho de que el ente denominado persona jurídica existe como tal y que su existencia genera consecuencias juridicas insoslayables. Biológicamente hablando, la constitución de la persona jurídica, su administración y los beneficios directos o indirectos que se deriven de su existencia, corresponderá a hombres, a seres humanos; no son ángeles, ni animales ni marcianos quienes desempeñarán esas funciones. Pero eso no quiere decir que, jurídicamente hablando, la persona jurídica sea una mera ficción ya que tal afirmación implicaría privilegiar sin justificación alguna la realidad biológica sobre la realidad juridica. $E$ incluso desde el punto de vista sociológico, podría sostenerse que esa doctrina constituye una expresión más del individualismo que reduce la sociedad y los grupos sociales a la suma de las personas naturales que los constituyen, dejando de lado el espíritu y los fines del grupo en tanto que tal.

Por otra parte, la opinión de Planiol se enfrenta con toda la doctrina del Derecho Civil y del Derecho Mercaniil. La noción de propiedad colectiva a la que alude es ininteligible dentro del contexto de nuestra concepción actual del Derecho. La única forma de propiedad colectiva que coriocemos es el condominio o propiedad indivisa. $Y$, sin embargo, esta figura jurídica no se aplica a las formas asociativas que implica la noción de persona jurídica. Los socios no son condóminos respecto del patrimonio de la sociedad. No existe un derecho real que vincule al socio con dicho patrimonio; el derecho real existe, como ya lo hemos dicho, entre la sociedad 
misma y su patrimonio. Según manifiestan Colin y Capitant, los partidarios de la idea de la propiedad colectiva para disolver la persona juridica en personas naturales dan fórmulas vagas $e$ imprecisas de esta propiedad porque "nada se parece menos a la propiedad propiamente dicha que el derecho (si hay alguno) de los miembros de una agrupación personificada sobre los bienes de ésta" (16). El socio de una sociedad anónima no tiene derecho alguno sobre el patrimonio social en tanto que la sociedad exista. Todo lo que le corresponde es un derecho de participar en los órganos de administración de la sociedad y en los beneficios de la empresa. Pero éstos son derechos personales de naturaleza fundamentalmente distinta a la del derecho de propiedad. La relación del socio con la sociedad anónima no está determinada por una presunta condición de copropietario de los bienes sociales sino por su calidad de accionista; la relación jurídica que lo vincula con los demás socios no es la de propiedad sino la de sociedad. Indudablemente, el socio es propietario de su acción. Pero esta acción es un título autónomo, jurídicamente distinto de los bienes de la sociedad, aunque económicamente su valor depende de ellos. El socio no es un propietario en común o condómino de los bienes de la sociedad sino que es un propietario individual de un bien diferente constituido por la acción. Esta acción la puede vender, puede percibir sus frutos y hacer cuanto le parezca con ella dentro de los limites establecidos por la ley; en cambio, no tiene poder alguno sobre los bienes sociales que solamente corresponden a la sociedad. No se trata, pues, de una indivisión, sino que los bienes de la sociedad constituyen un patrimonio distinto sobre el cual los socios no tienen ningún derecho exclusivo. Resulta evidente que si los socios fueran individual o colectivamente acreedores o deudores de terceros, nadie querría entrar en sociedad; y jurídicamente no lo son desde el momento en que la sociedad tiene su responsabilidad limitada. Asimismo, si cada integrante pudiera pedir la indivisión, pesaria todo el tiempo un peligro de muerte sobre la sociedad (17). Por consiguiente, carece de sentido jurídico preguntarse quién es el dueño "natural" de los bienes de la persona jurídica pues éstos, sean de una sociedad anónima o de una Empresa de Propiedad Social, carecen de dueño "natural" o individual.

16. COLIN, A. y CAPITANT, H.-Op. cit. N 819.

17. Ibid. No 819 .
Esta situación aparece muy clara cuando aplicamos el análisis a las fundaciones o a las Empresas de Propiedad Social, aunque es aplicable a toda forma asociativa que cree una nueva persona juridica. Una sociedad anónima emite títulos que dan origen a un derecho de propiedad de los socios; es verdad que éstos no son propietarios de los bienes del activo, pero al menos disponen de algo de lo que son dueños: la acción. En cambio, una fundación o una Empresa de Propiedad Social no dan lugar a derecho de propiedad alguno sobre nada para sus integrantes. Planiol y Ripert, al desarrollar la teoría de la propiedad colectiva, atribuyen el carácter de sujeto del derecho de propiedad en las fundaciones a "la colectividad de sus beneficiarios, que a menudo es la colectividad de los ciudadanos de la nación entera" (18). Pero Colin y Capitant acotan con agudeza que en los casos de fundaciones no es claro a quién puede pertenecer la propiedad colectiva, "a menos que se la atribuya a los pobres socorridos, a los enfermos curados, lo que seria una evidente confusión de ideas' (19). Creo que tanto Planiol y Ripert como Colin y Capitant han visto exactamente el problema y sus planteamientos no son incompatibles si distinguimos los planos: la propiedad de la fundación pertenece a la sociedad entera, como afirman los primeros; pero esto supone una confusión de ideas, como dicen los segundos, porque aquí se está usando el concepto de propiedad ya no en sentido jurídico sino en sentido sociológico.

La Empresa de Propiedad Social se asemeja en muchos aspectos a la fundación. Es una persona juridica $y$, por tanto, los bienes de su activo le corresponden a ella misma en propiedad. Nadie tiene derecho aiguno sobre un título que represente una parte del capital: los bienes constituyen una unidad económica a la que se le ha asignado un fin $y$ que es administrada -y también usufructuada, en el caso de las Empresas de Propiedad Social- por quienes en cada momento integran la persona jurídica. El "derecho de propiedad social" - -si se otorga este apelativo al derecho de los integrantes de la empresa a participar en su gestión y beneficios- no puede adquirirse por ninguno de los medios legales de adquisición de la propiedad: no cabe comprarlo, ni ven-

18. PLANIOL, M. y RIPERT, G.-Op. cit., I, No 68 , nota 1 .

19. COLIN, A. y CAPITANT, R.-Op. cit., N 819. 
derlo, no se puede llegar a ser integrante de la Empresa de Propiedad Social por prescripción. Cuando el socio de la Empresa de Propiedad Social -que sólo puede ser el trabajador de la misma- se retira, no le corresponde nada en compensación por su "propiedad"; a lo sumo, tiene una jubilación mejorada (arts. 123 a 131). Y, finalmente, cuando una Empresa de Propiedad Social se disuelve, los saldos de su liquidación no se distribuyen entre sus integrantes sino que pasan a formar parte del Fondo Nacional de Propiedad Social (art. 113, inc. e); en la misma forma como cuando una fundación se disuelve, sus bienes se transfieren a instituciones de fines análogos (arts. 68 y 69 del Código Civil).

\section{V}

La existencia de la persona jurídica como instancia titular de derechos puede ser negada también adoptando el punto de vista sociológico. En este caso, aun admitiéndose la realidad técnica de la persona juridica y aceptando las consecuencias que de ella se derivan, se intenta descubrir más allá de las formas jurídicas a las personas o al grupo que detentan efectivamente los bienes puestos al servicio de una actividad económica determinada a través de la Empresa de Propiedad Social.

Evidentemente, el análisis sociológico sólo puede ser un análisis empírico: habrá que ver dentro de la experiencia concreta quién ejerce el poder de decisión permanente y exclusivo; puede ser el Estado debido a la magnitud de su intervención, o quizá las Unidades Regionales detrás de las cuales habrá que investigar a su vez los intereses que se ocultan, o el grupo de trabajadores que laboran en la empresa. Ahora bien, aun cuando la respuesta concreta depende de la investigación empírica, podemos decir quién debería ejercer esta "propiedad sociológica" dentro de los lineamientos de la idea de la propiedad social. $Y$, desde esta perspectiva, la respuesta también es clara. Luego de negada como hipótesis la existencia legal de la persona jurídica, nos encontramos que la "propiedad" no le corresponde tampoco al grupo de trabajadores, ni al Sector, ni al Estado. En realidad, no le corresponde a nadie. No existe una persona o personas físicas en quienes se reúnan todos los atributos de la propiedad, una vez que hemos suprimido la intermediación de la persona jurí- dica. $Y$ como propiedad de nadie es propiedad de todos, podriamos decir que es en este sentido que cabe hablar de propiedad "social"; aun cuando quizá sería más propio reconocer simplemente que en este caso la categoria de la propiedad ha sido desbordada y las relaciones sobre el uso de esos bienes deben interpretarse con la ayuda de esquemas teóricos totalmente diferentes a la propiedad. En esta forma, habríamos encontrado a este nivel una diferencia radical con la sociedad anónima y otras formas empresariales en las que, puesta de lado la persona juridica, nos encontramos que estamos frente a verdaderas propiedades colectivas (sociológicamente hablando).

La propiedad social no corresponde al grupo de trabajadores que en un determinado momento prestan servicios para una empresa porque éstos carecen de dos de las características esenciales de la propiedad: la perpetuidad del derecho y la autonomía del mismo. Los trabajadores ejercen los derechos de gestión, percepción de frutos y disposición de los bienes; con todas las limitaciones, evidentemente, que ya hemos señalado y que recortan su derecho pero que no alteran su esencia. Pero estos derechos no son permanentes ni autónomos pues dependen de su condición de trabajador. En la propiedad social, los derechos mencionados no se ejercen por el hecho de que el titular es dueño de una parte del capital (es decir, en su condición de propietario), sino que son meros elementos derivados de una relación personal previa (la condición de trabajador). Se infringe así el principio de autonomía: la cosas no se poseen "como propietarios" sino como trabajadores. Y lo que es más grave: esta condición de trabajador no es permanente; dura lo que dura la prestación de servicios. Por consiguiente, los derechos de gestión, percepción de frutos $y$ disposición son igualmente temporales, mientras que la propiedad se define como el ejercicio de derechos sin plazo. Aún más, cuando la sociedad anónima se disuelve, el accionista -que podría ser considerado dueño desde el punto de vista sociológico por cuanto que su derecho es autónomo de toda otra relación y se basa en el hecho de poseer exclusivamente como propietariorecibe una parte del haber social; en esta forma, su derecho de propiedad sociológico se perpetúa aún después de que ha desaparecido la persona juridica. En cambio, el integrante de una Empresa de Propiedad Social no tiene nunca derecho a parte alguna 
del capital y, cuando se retira o cuando la sociedad se disuelve, no recibe nada.

La propiedad social no corresponde tampoco al Sector ni al Estado porque éstos, como se ha dicho antes, no tienen derecho de disposición ni de administración alguno sobre los bienes sociales. Todo su papel se limita a controlar o a aprobar el ejercicio de estos derechos por los integrantes de la empresa, como lo hace normalmente el Estado en muchos aspectos de la vida de una persona jurídica de Derecho Privado (sociedad, asociación, fundación). La iniciativa -el derecho de disposición, propiamente- queda en manos de los trabajadores de cada empresa, los que, según se ha explicado, tampoco pueden ser considerados como dueños por este solo hecho. Además, si hemos negado como hipótesis la existencia de la persona jurídica llamada Empresa de Propiedad Social para los efectos de conocer qué personas naturales y qué intereses controlan efectivamente esos bienes, debemos hacer lo mismo con todos los demás entes juridicos. De manera que si queremos ser consecuentes con esos planteamientos, hay que reducir también el Estado a las personas e intereses que efectivamente lo controlan en un momento histórico determinado. De esta manera, de nada nos serviría hablar de propiedad estatal pues, para emitir un juicio de valor sobre ella y para saber estrictamente lo que represenía, haría falta preguntarse a quién sirve dicho Estado; solamente así sabríamos en forma más precisa quién es el verdadero "dueño" de las Empresas de Propiedad Social.

Por consiguiente, de todo 10 expuesto aparece que si negamos la existencia de la persona jurídica que es titular directa del derecho de propiedad social sobre los bienes de una Empresa de Propiedad Social, nos encontramos que no hay entonces otro "dueño" de tales bienes. El conjunto de facultades que constituye la propiedad se encuentra desarticulado y difundidas sus partes entre los distintos componentes del sistema de Propiedad Social; y algunas de las características esenciales de la propiedad -como la perpetuidad del derecho- han desaparecido por completo. La única instancia sociológica que parece gozar de un derecho permanente sobre esos bienes es la sociedad en su conjunto; es en ese sentido que se dice que propiedad social es la propiedad de la sociedad. Sin embargo, estamos muy lejos del concepto clásico de propiedad, al punto que podríamos aban- donar el término para designar esta nueva situación; esto evitaría incluso muchas confusiones. Podría asi declararse simplemente que, independientemente del sentido que hemos mencionado relativo a la persona jurídica que funge de propietaria, estas empresas no están organizadas en torno al derecho de propiedad. Las categorías de propiedad privada o estatal no son aplicables a esta forma de organizar la producción económica. En realidad, las Empresas de Propiedad Social serían únicamente unidades económicas, compuestas por un conjunto de bienes necesarios para realizar una determinada actividad productiva, que la sociedad coloca a disposición de quienes en cada momento los hacen funcionar, es decir, a disposición de sus trabajadores; evidentemente, dentro de ciertas condiciones. Este planteamiento que niega la ubicuidad del derecho de propiedad puede desconcertar a quienes están acostumbrados a encontrar una relación de propiedad debajo de cada relación social en el uso de los bienes; a estas personas les repugna la idea de bienes sin dueño. Sin embargo, ya hemos señalado que en el terreno técnico del Derecho, la desvinculación entre la propiedad y el uso efectivo de los bienes comienza con el desarrollo de las formas asociativas de empresa $y$, en particular, de la sociedad anónima; la empresa constituida sobre la idea del "propietario natural" clásico queda relegada a la empresa unipersonal con muchas características todavía de la producción ariesanal, pero la figura de ese "propietario" clásico está ausente de la moderna empresa capitalista.

Ante estas nuevas tendencias organizativas se hacen necesarias nuevas categorias que expliquen mejor la naturaleza de las relaciones efectivas. En este sentido, es posible que la teoría de la Institución de Hauriou susiituya con ventaja a la explicación mediante la idea de propiedad. La Empresa de Propiedad Social es una "institución" típica, en el sentido de Hauriou: es un patrimonio afectado a un fin, y nada más; categoría que, por otra parte, no es nueva en nuestro ambiente jurídico pues la recoge ya el artículo 64 de nuestro código Civil de 1936 para definir a las fundaciones.

\section{VI}

Desde ya anticipamos una objeción a todo el planteamiento que antecede: el concepto de propiedad 
que se ha usado como parámetro para determinar que la propiedad social no es propiedad, es demasiado restringido. Dentro de este orden de ideas puede decírsenos que a lo largo del presente trabajo la propiedad ha sido definida con categorias liberales; hemos entendido bajo esa denominación solamente la propiedad privada clásica. A partir de ese punto de vista, fácil es demostrar que la propiedad social no encaja dentro de tal concepto; $y$, como esta institución ha sido limitada a esa propiedad liberal, pareceria que la propiedad social no es propiedad en absoluto. En otras palabras, la objeción puede plantearse en los siguientes términos: (a) la propiedad privada clásica no es "la" propiedad; por consiguiente, (b) el hecho que la propiedad social no sea propiedad privada clásica no significa que no sea propiedad en absoluto; (c) la tarea actual debe ser redefinir la noción de propiedad a fin de que permita incluir sus formas socialistas, entre las que se encontraria la propiedad social.

Existe indudablemente dentro de nuestra formación una tendencia a absolutizar los conceptos y a definir metafísicamente las instituciones juridicas y sociales, a fin de encontrar una universalidad y permanencia que constituye la expresión de un cierto anhelo recóndito de estabilidad y seguridad. Es así como se pretende encontrar una definición de Derecho que pueda abarcar todos los fenómenos sociales normativos de la humanidad, desde el "Derecho" de las tribus de la Polinesia hasta el Derecho de las grandes Corporaciones Multinacionales capitalistas, desde las leyes de Manú y el Código de Hammurabi hasta la sofisticada legislación tributaria moderna; o descubrir preceptos "jurídicos" universales, tales como "no matar", "dar a cada uno lo suyo" (suum cuique tribuere), "respetar las promesas" (pacta sunt servanda), etc. Dentro de esta misma línea, juristas de todas las ideologías han perseguido una noción de propiedad que sea suficientemente abarcante como para comprender todas las formas que la humanidad ha desarrollado de apropiación de los bienes naturales. Hay ciertas formas de apropiación que han resistido siempre a ser categorizadas como propiedad; este es el caso, por ejemplo, del aprovechamiento del aire que se respira. Sin embargo, a fuerza de adelgazar el concepto se ha logrado por algunos autores definir la propiedad de manera que comprenda tanto el derecho del pescador primitivo sobre el producto de la pesca como el derecho del accionista sobre su acción, el derecho del Estado sobre los medios de producción en los paises socialistas como el derecho del inventor sobre su invento en los países capitalistas.

Es notable que incluso algunos autores marxistas, de ordinario tan celosos del enfoque histórico, han caído en la misma tentación bajo formas sutiles. El más destacado de ellos, Karl Renner (20), cree que la noción jurídica de propiedad es relativamente inmutable, al igual que otras instituciones juridicas fundamentales; lo único que cambia es su uso social. Renner piensa que la sociedad usa las instituciones legales como el constructor usa los ladrillos: puede hacer con ellas muchas cosas, como una casa, un edificio, etc.; pero los lipos de ladrillos con los que cuenta son limitados y estos tipos son siempre los mismos. En el fondo, la posición de Renner refleja una herencia kantiana que distingue entre forma $y$ contenido, entre categoria e historia; herencia que se traduce en un positivismo jurídico, de corte marxista pero slempre positivismo. Las instituciones jurídicas se le aparecen como marcos vacíos, como puras formas, independientes de su sustrato económico-social, que son llenadas con diferentes contenidos; la historia sólo tiene lugar a nivel de estos contenidos.

Creo que este tipo de nociones cuya universalidad se ha conquistado a base de despojar a los términos de sus contenidos concretos, no son aceptables. En muchos casos, tales conceptos globales tienen una función decididamente ideológica pues ocul$\tan$ la verdadera naturaleza de las relaciones entre los hombres; en los mejores casos, son nociones perfectamente inútiles. Las cosas son lo que son sus formas concretas. $\mathrm{Y}$ la búsqueda de lo universal no agrega nada al conocimiento humano cuando para lograrla se paga el precio de perder la riqueza y la complejidad de lo real al punto que el concepto se convierte en una fórmula vacia: el ser y la nada se tocan, cuando para definir el ser necesitamos suprimir todas las determinaciones de la realidad. De poco nos sirve la regla aparentemente universal que prescribe "no matar", cuando no se precisan las condiciones de aplicación de la pena de muerte, el sentido de la legítima defensa y el derecho a la guerra. De nada nos sirve aceptar que hay que "dar a cada uno lo suyo" cuando la definición de "lo suyo" puede dar origen a sistemas y a derechos radicalmente

20. RENNER, Karl.-“The Institutions of Private Law and their Social Functions", 1945. 
diferentes. Afirmar que el Derecho es el "orden normativo que regula las conductas externas de los hombres" no nos ayuda en lo menor para entender las diferencias -realmente sustanciales- entre la legalidad liberal-capitalista y la legalidad socialista. Este tipo de esfuerzos teóricos equivale a pretender encontrar una definición de "vehículo" que pueda aplicarse por igual a la cuadriga romana y a un Alfa Romeo, al kayak esquimal y a una nave espacial; indudablemente que todo ello caería en la categoría de vehículos, pero esa noción general nos serviría de poco para entender lo que verdaderamente es el Apollo XIV. Y si un ingeniero mecánico consagrara su formación a aprender ese tipo de conceptos universales, difícilmente podría reparar el motor de su automóvil.

Lamentablemente, muchos abogados somos proclives a esa perspectiva a-científica. $Y$ es así como construímos conceptos universales de los que nos sentimos muy orgullosos, pero que son inutilizables y que en la práctica profesional se sustituyen por un enfoque marcadamente positivista que proporciona nociones muy específicas de cada institución a través de una análisis minucioso del orden jurídico vigente. En el presente trabajo hemos tratado de evitar la utilización de una idea de propiedad que constituya un lugar común hueco, sin especificidad alguna. Por eso, hemos definido la propiedad en los términos de la propiedad liberal clásica adoptándola como patrón de referencia porque constituye el centro de nuestra experiencia histórica: la "propiedad" de épocas históricas anteriores rec:be tal apelativo sólo como prefiguración de la propiedad liberal; y la "propiedad" que se presenta como alternativa a la propiedad liberal es considerada propiedad sólo por exlensión de ésta. Dentro de este orden de ideas, resulta justificable que aquellas formas de apropiación social de los bienes que se alejan suficientemente de la propiedad liberal clásica, no sean llamadas propiedad.

\section{VII}

Como conclusión de este análisis podemos afirmar que la propiedad social no existe; o, más precisamente, que no es propiedad.

Desde el punto de vista jurídico, de lo que se trata es de crear una nueva forma de organización em- presarial, una nueva persona jurídica con características originales que modifican algunos conceptos del Derecho de Personas. Pero no se está creando ningina forma nueva de propiedad, no hay novedad alguna en materia de Derechos Reales. La nueva persona jurídica denominada Empresa de Propiedad Social -que hubiera sido posible denominar más simplemente, aunque con menor fuerza evocativa, "Empresa Social" - es propietaria de sus bienes en la misma forma como las demás personas juridicas ya conocidas por el Derecho vigente; las limitaciones que específicamente la afectan, no alteran la sustancia de su derecho de propiedad.

Si nos olvidamos de la existencia de una persona independiente y nos preguntamos simplemente por el hecho social de la apropiación de los bienes, tampoco podemos encontrar aquí una propiedad de los trabajadores, del Sector o del Estado. La situación es más bien parecida a la de la fundación, que no tiene dueño sino que es un patrimonio afectado a un fin determinado y admministrado por ciertas personas. A lo sumo, podriamos hablar de una propiedad de la sociedad; de ahi la expresión - sociológica y no jurídica- de "propiedad social". Pero esta propiedad de la sociedad difiere a tal punto de la idea clásica de propiedad que mejor sería abandonar el concepto a fin de evitar confusiones; y estas confusiones son manifiestas en la discusión pública producida en torno al Anteproyecto de Ley.

Para los efectos de tomar posición frente al Anteproyecto de Ley, parecería metodológicamente más adecuado discutir directamente la naturaleza de los derechos de cada una de las partes involucradas en la organización de la Empresa de Propiedad Social y la justificación social de las limitaciones que se establecen, sin intentar encajar estos derechos y obligaciones dentro de estructuras conceptuales prefabricadas como la idea de propiedad. En todo caso, las relaciones de propiedad en torno a la Empresa de Propiedad Social podrian estar mejor expresadas si se sustituyera la actual redacción del artículo $33^{\circ}$ del Anteproyecto, por otra del tenor siguiente:

“Artículo $3^{9}$.-La propiedad es social por cuanto que es un patrimonio de la sociedad afectado a los fines de la presente ley.

Los derechos jurídicos de propiedad sobre los bienes del activo de las Empresas de Propiedad Social los ejerce cada empresa como persona ju- 
rídica independiente, dentro de las limitaciones que esta ley establece".

A partir de ahí, podriamos olvidarnos del problema de la propiedad y debatir más útilmente sobre si la Empresa de Propiedad Social asegura una mayor o meior participación de los trabajadores en la gestión y utilidades que la empresa privada, si el interés de la sociedad en aumentar las oportunidades de empleo puede cumplirse a través de esta nueva forma de or- ganización empresarial, si el principio de solidaridad y la justicia distributiva son realizables en el interior de una economia de mercado, y otros temas similares. En cambio, la discusión sobre si la Empresa de Propiedad Social es propiedad de los trabajadores, del Sector o del Estado es tan estéril como las discusiones medievales sobre el sexo de los ángeles. 